\title{
Breves reflexões sobre o percurso de vida e a identidade de uma escritora francesa da Idade Média: estudo de caso.
}

\author{
Ida Lucia Machadol
}

\begin{abstract}
Resumo: O objetivo principal deste artigo é o de propor algumas reflexões sobre a enigmática figura de Marie de France, de cuja vida se sabe pouca coisa até o momento presente. Possivelmente, viveu e escreveu na corte de Henrique II, na Inglaterra, na segunda metade do século XII. Para expor uma pequena parte de sua narrativa de vida seremos obrigada a levar em conta as poucas informações biográficas encontradas sobre ela, contornando as lacunas pela observação de seu discurso escrito. Para tanto, partiremos de alguns conceitos da análise do discurso para realizar uma possível interpretação de uma versão para o português do seu poema, o "Lai da Madressilva". Acreditamos que ao observar pistas deixadas em sua escrita, tocaremos- de certo modo- em sua personalidade. Além de examinar os "eu(s)" (ou sujeitoscomunicante e enunciador) que comandam/atravessam esta narrativa lírica, abordaremos alguns imaginários sociais e culturais que circulavam na época em que o poema foi escrito.
\end{abstract}

Palavras-chave: sujeitos discursivos; percurso de vida; narrativa lírica; identidade

Neste artigo, gostaríamos de mostrar a validade de alguns conceitos vindos da análise do discurso que praticamos ${ }^{2}$, quando aplicados na apreensão crítica de certos textos literários. Entre outras categorias discursivas, tais conceitos podem nos ajudar a chegar perto da identidade do autor ou sujeito-comunicante de determinadas produções escritas. Para tanto,

1 Ida Lucia Machado é doutora ès Lettres pela Université de Toulouse II (Jean Jaurès) na França. Atualmente é professora no PosLin/FALE/UFMG, onde ministra cursos e orienta teses e dissertações em Análise do Discurso (AD). Autora de vários artigos, coletâneas e livros sobre AD e sua aplicação em diferentes corpora, publicados no Brasil, França e Portugal. Levou cerca de cem alunos (mestrandos e doutorandos) à defesa, no PosLin. Criou o Núcleo de AD da UFMG. É pesquisadora 2 do CNPq em análise do discurso e narrativas de vida.E-mail: idaluz@hotmail.fr.

2 Trata-se da Semiolinguística, teoria criada por Charaudeau (1983, 1992). Nela interessa-nos o quadro enunciativo construido pelo linguista que vê todo e qualquer discurso comportando dois espaços: um "externo", o espaço do "Fazer", no qual se situam o sujeito-comunicante e o sujeito-interpretante ou, em outros termos, o autor (com seu projeto de escrita, sua situação psicossocial face ao mundo que vai contar) e o leitor-real (com seu projeto de leitura, sua situação psicossocial face aos escritos que vai (re)interpretar pela sua leitura); um espaço "interno", o do "Dizer", no qual se movimentam e "falam" os protagonistas dos atos linguageiros, nomeados sujeito-enunciador (ou narrador) e sujeito-destinatário. Estas duas identidades foram concebidas pelo sujeito-comunicante (ou autor). Além disso, a teoria concede um lugar privilegiado aos imaginários sociais e culturais, às identidades e organizações do discurso, entre outros pontos. A Semiolinguística é uma teoria que possui um instrumental rico e fácil de ser aplicado em diferentes corpora e além disso tem a característica de ser interdisciplinar, pois não se fecha à inclusão de conceitos vindos de outras disciplinas, tais como a sociologia, a psicologia social, a antropologia, a teoria literária.

Gláuks: Revista de Letras e Artes - jan/jun. 2019 - Vol. 19, $N^{o} 1$ 
utilizaremos aqui um poema ou uma forma de narrativa lírica da Idade Média ilustrar o que foi dito, utilizaremos aqui um dos escritos de Marie de France, poetisa cuja história de vida ${ }^{3}$ ainda é misteriosa, ou seja, há poucas coisas que se podem afirmar, com relativa segurança, sobre sua pessoa. Já foram levantadas várias suposições sobre a identidade dessa escritora ${ }^{4}$, mas, nenhuma delas ainda foi realmente provada. Resta-nos seu talento artístico que pode ser entrevisto em seu modo de narrar, nas palavras de seu sujeito-enunciador ${ }^{5}$ ao nos contar lendas e mitos vindos dos Celtas, paulatinamente incorporados à chamada Matéria da Bretanha ou Literatura Arturiana (BERTHELOT; CORNILLIAT, 1988, p. 72), cuja popularidade foi grande na Europa.

A escritora/poetisa supracitada narra histórias de um mundo mítico sobre a forma de poemas ou lais. Dito de modo bem resumido, o lai corresponde ao nome que foi dado, na época de Marie de France (século XII) às composições poéticas, fossem estas líricas ou narrativas, o que torna sua definição um pouco ambígua. Vamos aqui partir do princípio que os lais ou poemas de Marie de France podem ser vistos como narrativas líricas, já que contam histórias sobre as aventuras de seres cuja lembrança se que perpetuar.

O mais conhecido deles é o Lai du chèvrefeuille, na tradução para o português $L a i^{6} d a$ madressilva, que aborda o mito do amor eterno, vivenciado pelos personagens Tristão e Isolda. Tal história foi contada/recontada/cantada por trovadores e narradores diversos, oralmente ou por escrito, ou seja, a história dos dois amantes já fazia parte do cultura da época de Marie de France. Talvez essa seja a razão que a levou a "resumir" em dez versos a lenda logo no início da narrativa para, em seguida, narrar um dos muitos encontros ocorridos entre os dois amantes, sem se preocupar com uma descrição minuciosa da história em seu todo. Nessa delicada visão feminina lançada sobre uma história de amor deve-se notar os primeiros dez versos que sintetizam habilmente todo o drama dos jovens amantes lendários e seu desfecho mortal.

Evidentemente, a análise do discurso Semiolinguística não possui bases mágicas que nos levarão ao pleno conhecimento da vida de Marie de France. Mas, alguns de seus conceitos poderão nos guiar para verificar o como e o porquê da escrita dessa autora, por meio da

3 Pelo menos até o momento em que escrevemos este artigo e o enviamos à revista.

4 Pelo que já foi dito sobre Marie de France, queremos crer que se trata de alguém do sexo feminino. 5 Ver nota 2.

6 Preferimos manter a denominação lai, bem característica da época e da produção de Marie de France, no lugar da palavra "poema". 
observação tanto das palavras por ela como pela sua disposição na narrativa lírica. Movidos pela análise do discurso escolhida, seremos levados a avaliar os artifícios retóricos utilizados para se criar a ilusão de que a ficção narrada realmente aconteceu; consideraremos também que foi justamente a escolha verbal e o cuidado na criação dessa obra que lhe deram força para transpor séculos e chegar até nós. Há nessa narrativa lírica pistas que podem nos conduzir, de modo sutil, a alguns traços identitários do indivíduo que a escreveu.

De modo implícito, as palavras escolhidas pela poetisa para contar parte da história dos dois amantes traduzem ideologias vigentes na época ou como afirma Charaudeau (2005, p.143-157) imaginários sociais, discursivos e culturais que foram observados e vivenciados pela própria Marie de France, enquanto membro de determinada sociedade em determinada época. Nesse caso, a análise do discurso nos permite criar um "possível interpretativo" (CHARAUDEAU, 1983, p. 56) ao empreender uma viagem pelas palavras, assumindo uma busca que tem o poder de abolir o tempo e deixar nossa imaginação penetrar na segunda metade do século XII, quando da aparição do lai. O fato é que :

[...] esses textos estavam intimamente ligados a um modo de pensar a vida humana, e a configuração dessa visão de mundo permaneceu ao longo do milênio, renovada sempre que algum escritor reescreveu tais histórias. Ler esses textos é não só voltar à própria infância, mas também à do homem ocidental. (AMORIM, Revista Olhar, ano 2, número 3, junho/2000, p. 2)

Esta citação concorda com uma de nossas ambições, no presente artigo: a de oferecer, aos leitores de hoje, ainda que de forma bem panorâmica, a visão de alguns sentimentos e do modo de conceber a vida predominante na "infância do homem ocidental" (op.cit) e também a de fazê-los tomar consciência de que pessoas que viveram em um passado tão longínquo tinham suas identidades sociais e culturais; curiosamente, em alguns casos elas se aproximam das nossas, nos dias de hoje.

Aliás, grande parte dos textos literários produzidos na Idade Média, carregam consigo muito mais que simples informações sobre os seres que lutavam pela sua sobrevivência em uma sociedade feudal repleta de castas e de desigualdades. Se lermos tais textos à luz das disciplinas discursivas, observando seus implícitos, ficaremos surpresos por neles encontrar elementos que conduzem não apenas à vida política da época mas também, a críticas veladas sobre as ideologias professadas pela classe nobre, pela aristocracia. Isso nos leva a refletir que o ser humano é sempre o mesmo, ávido pelo poder, dividido entre o bem e o mal, essa ou 
aquela religião ou crença. A análise do discurso, na interpretação ou leitura de textos literários medievais ou textos literários em geral, procura explicitar quem são os sujeitos da linguagem que ali circulam, sem se esquecer das identidades dos indivíduos que os criaram e os colocaram em cena. Pois, mesmo ao escrever uma ficção, o autor(a) deixa ali algo de si, de seu itinerário de vida.

O artigo será dividido em três segmentos, nos quais buscaremos explicar nossa visão como pesquisadora de análise do discurso e narrativas de vida, sejam elas fictícias ou reais. Neles abordaremos o que foi encontrado (até agora) sobre o percurso de vida de uma mulher escritora da Idade Média, pela leitura e interpretação - cuja subjetividade assumimos - de um de seus escritos. Discutiremos também a noção de identidade, segundo Charaudeau (2009), Kaufmann (2012) e Machado (2016).

\section{Alguns comentários sobre a vida e obra de Marie de France e sobre o lugar de onde ela falava/escrevia}

Como já anunciamos, faltam-nos elementos biográficos que indiquem com precisão a história de vida da poetisa ou da pessoa que assinava Marie de France, na segunda metade do século XII. Avançamos pois, tateando, um pouco às escuras, com cuidado para não propor informações ainda não verificadas.

Ao que tudo indica, trata-se de uma mulher, bastante moderna e ousada para a época, primeiramente por ser alguém de grande cultura, conhecedora e tradutora do latim e também por ser alguém que viveu entre a Inglaterra e a França. Assim, Marie de France pode ser enquadrada na literatura que agora chamamos de anglo-normanda, como outros escritores que viveram certo tempo na Inglaterra ou lá nascerem e que tinham como língua escrita o francês da Normandia. Segundo Amorim,

\footnotetext{
A designação literatura anglo-normanda se deve ao fato de que a Inglaterra e a Normandia, nesse periodo (séculos XII-XIII), constituíam um único reino (desde a conquista da ilha pelo duque Guilherme da Normandia, em 1066).

É na segunda metade do século XII, durante o reinado de Henrique II Plantageneta (que governou de 1154 a 1189) e de Alienor da Aquitânia, sua mulher, que floresceu a produção literária mais significativa da Idade Média francesa. Henrique II era rei da Inglaterra, duque da Normandia, conde de Anjou e duque da Aquitânia em nome de sua mulher - seu reino estendia-se da Escócia aos Pirineus; foi um mecenas que se cercou de escritores de primeira linha. Alienor, por sua vez,
} 


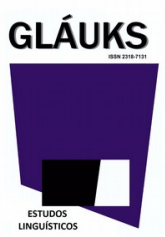

era neta de Guilherme IX da Aquitânia, o mais antigo trovador conhecido. [...] É para Henrique e para Alienor que são escritas as principais obras dessa época: o Roman de Brut, de Wace; o Roman de Thèbes, o Enéas, os dois Tristan (o de Thomas e o de Béroul), os Lais de Marie de France, os romances de Gautier d'Arras, o Roman de Troie, de Benoît de Saint-Maure. (AMORIM, 2000, p. 2)

Foi nesse espaço que Marie de France viveu e escreveu: em um ambiente onde dominava a cultura, protegida e incentivada por um soberano e sua esposa. Um meio intelectual propício à concepção de lais narrativos como os que Marie de France assina. O mais curto deles é aquele que escolhemos para o artigo, ou seja o do Chèvrefeuille, ou madressilva, em português: com apenas 118 versos, o lai tem e a importante função de trazer à tona uma visão feminina sobre a famosa história ou mito (de fundo celta) de Tristão e Isolda, além de "facilitar o aparecimento do ciclo arturiano dos romances de cavalaria, tanto na França quanto na Inglaterra” (AMORIM, 2000).

Para a medievista Berthelot (1988, p.92-94) existe a suposição de que a Marie de France, a autora dos lais tenha nascido na França e vivido entre viagens para a França e para a Inglaterra, já que, em uma de suas composições poéticas, ela se apresenta e diz o seguinte: "Marie ai nom, si sui de France". Traduzindo: "Chamo-me Marie e sou da França". Mas, mesmo tal informação pode ser interpretada de diferentes modos: ela estaria se referindo ao país ou a uma de suas regiões (Île de France)? Poderia também ter reivindicado a França como sua pátria por uma questão de amor ao lugar. Tudo é nebuloso, nesse sentido.

Existem várias personagens históricas, entre elas uma filha de rei Louis (Saint Louis) que tinham como nome Marie. Mas não se sabe se alguma delas foi realmente a escritora que agora nos interessa. Seja como for, ela escreveu durante a segunda metade do século XII. Levando em conta a vasta produção literária realizada na corte de Henrique II, preferimos situá-la, enquanto escritora, na Inglaterra.

Para Berthelot (1988) sua obra principal seria uma coletânea de lais, ou seja, textos curtos em versos, cujos temas eram inspirados nos chamados “contos bretões". Talvez ela seja também a autora do Espurgatoire de Saint Patrice, narrativa meio celta, meio cristã eu conta a viagem do santo ao outro mundo. E ainda, é bem possível que seja também a autora de um Ysopet, ou seja, uma coletânea de traduções (à moda medieval) de fábulas de Esopo.

Devemos confessar que, para este artigo, ficamos em dúvida quanto a tradução a utilizar. Hesitamos entre o Lai du chèvrefeuille ou seja, a tradução do poema original, escrito 
em língua anglo-normanda para o francês moderno, feita pela já citada medievista Berthelot (1988, p. 92-94) e a tradução feita pelo literato brasileiro, Orlando Nunes de Amorim, em artigo disponibilizado na Internet ${ }^{7}$. Enfim, achamos que a segunda tradução ficaria mais de acordo com nosso artigo (escrito em português).

\section{Reflexões sobre alguns segmentos do lai da Madressilva}

Sem mais tardar, observemos alguns fragmentos do corpus. A eles se seguirão algumas reflexões sobre o estilo de escrita de Marie de France e suas influências sóciodiscursivas, enquanto indivíduo/escritora da segunda metade do século XII.

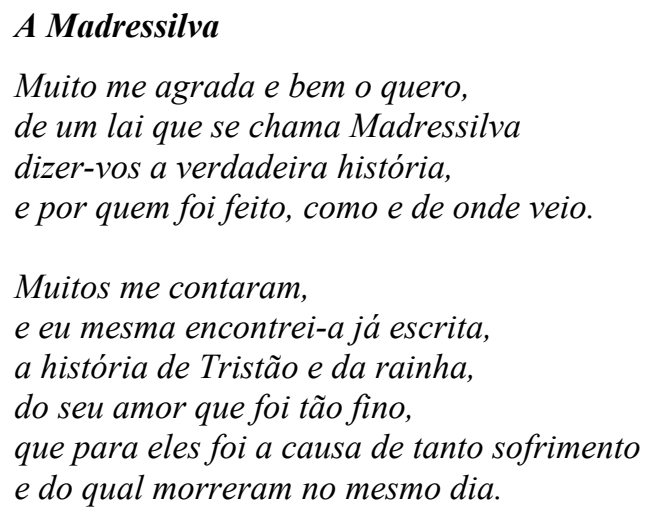

Note-se, nos dez versos iniciais do lai, que a poetisa busca e aplica uma estratégia literária que era bem comum aos escritores da época, mas que vemos ainda hoje, em certas narrativas. Ela tenta reforçar o fato de que não vai inventar nada que já não tenha sido dito e escrito: assim agindo, ela procura envolver o leitor (ou o ouvinte) na história narrada, certamente recitada ou cantada na época da autora. Ao mesmo tempo, é curioso notar que ela é sincera, pois, realmente, em relação a tais versos, não inventa nada: a história dos dois amantes já era bastante conhecida pelo seu público, logo, seria enfadonho repeti-la. Voltemos aos três primeiros versos,

Muito me agrada e bem o quero, de um lai que se chama Madressilva

7 Conforme Amorim, in: www.ufscar.br-revistaolhar/pdf/olhar3/09MADRESSILVA.pdf, consultado dia 13 de janeiro de 2019

Gláuks: Revista de Letras e Artes - jan/jun. 2019 - Vol. 19, $N^{o} 1$ 
dizer-vos a verdadeira história,

e por quem foi feito, como e de onde veio

que ilustram uma espécie de promessa que foi por ela cumprida. Há por parte dessa escritora e de outros escritores medievais (como Chrétien de Troies) um grande respeito pelo leitor ou ouvinte, por eles considerado como interlocutor. Tal cuidado para provocar um "efeito de realidade" (CHARAUDEAU, 1992, p.695; MACHADO, 2016, p.126) dentro da ficção narrada é um fator importante para nos mostrar o imaginário estilístico-discursivo da época da produção escrita. Ou ainda, como diria Charaudeau (2005, p. 157), parte do imaginário sociodiscursivo que predominava na mente de uns e outros. Tais imaginários circulavam em um espaço de interdiscursividade, de troca de saberes.

Seja como for, por meio desses procedimentos, Marie de France coloca em cena uma narradora que permite que outras vozes entrem em seus escritos, dando lugar a trocas polifônicas, como diria Bakhtin (1970). Em outras palavras, há algo de modernidade em uma escritora do século XII ao reivindicar não ser a única proprietária da história que narra, subentendo que tal narrativa acolherá outras vozes ${ }^{8}$ que a sua.

Nos versos seguintes, a escritora começa a "sua" versão da história. Ela parte de sua imaginação feminina para colocar em cena um dos muitos encontros clandestinos que (dizem) Tristão teve com Isolda, a mulher amada, esposa do rei Marcos a quem Tristão devia respeito e obediência. Assim, nos versos 11-30, após contar as tristezas de Tristão com sua expulsão do reino de Marc e seu exílio forçado na floresta, durante um ano, ei-lo que não suportando mais a falta de notícias de Isolda, sai ao cair da noite. Quem transmite as novas são camponeses, como podemos ver nos versos $31-45$, a seguir:

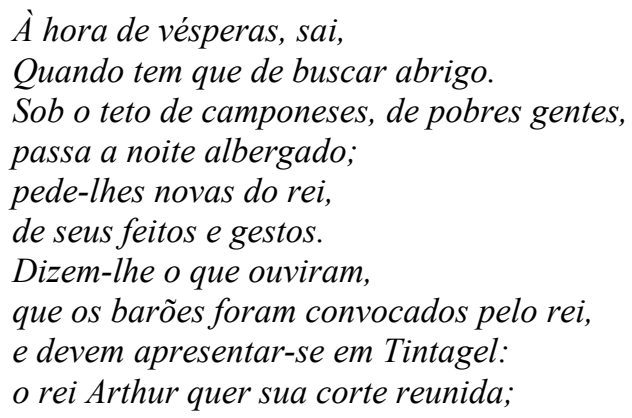

8 Sobretudo as de Beroul e Thomas. O primeiro era um poeta francês e o segundo era inglês. As primeiras versões escritas da lenda de Tristão e Isolda são a eles atribuídas. Em sua essência a história é praticamente a mesma. Mas, na versão de Beroul, Tristão não era nobre: apenas um bravo cavaleiro que vai a Irlanda buscar Isolda para que esta se case com seu rei. 
no dia de Pentecostes, todos lá estarão,

haverá muita alegria e divertimento,

e a rainha lá estará.

Tristão, ao ouvir essas novas, muito se alegrou:

a rainha não poderá para lá ir

sem que ele a veja passar.

Conforme afirmamos, no início do artigo, Marie de France utiliza em seus escritos e, sobretudo, para o lai em questão, temas vindos da "literatura Arturiana". Eis um índice que nos remete ao imaginário discursivo e coletivo em voga na segunda metade do século XII: contar algo sobre o lendário rei era um índice seguro de agradar os ouvintes e leitores da época. Arguta, a poetisa provavelmente sentiu que, ao narrar algo vindo desse imaginário mítico receberia a aprovação de seus mecenas e cortesões. Pode ser também que o poema tenha sido uma encomenda da própria realeza, como acontecia muito na época.

Chamou-nos a atenção o fato de apenas um verso - "o rei Arthur quer sua corte reunida"- ser o único que menciona o rei, seu poder de comandar. Haverá nisso alguma crítica irônica ao mundo que cercava a escritora? Difícil afirmar com segurança. Mas, a dúvida é cabível: pela sua maneira de escrever, Marie de France deixava entrever a força do sistema político dominante, do qual ela mesma fazia parte e com o qual devia conviver. No sistema feudal, havia um soberano que dominava todos os outros. Ora, no poema em pauta, o marido de Isolda era rei mas, um "rei menor" pois, devia obediência cega aos mandos e desmandos aos caprichos- do "rei maior", ou seja, Arthur. Mesmo se os personagens do poema emanam de um mundo fictício, a História mostra que houve uma nobreza composta por senhores feudais e pode provar - com documentos de arquivos e outros - a existência/aplicação de tal sistema.

Nos versos 51-54, eis como a narradora descreve a estratégia de Tristão para se fazer notar por Isolda e, talvez, para ter um encontro com a amada:

[Tristão] parte ao meio um galho de avelaneira e talha o ramo para desbastá-lo.

Depois de preparar o ramo,

com sua faca nele grava o seu nome.

Como Amorim (2000) já notou, eis outro mistério do lai: Tristão grava no ramo seu nome ou o de Isolda? Tal mistério não é esclarecido, nem tampouco o do conteúdo dessa mensagem cifrada, como mostram os sétimo e oitavos versos abaixo transcritos. Tristão gravou apenas seu nome? Ou uma mensagem foi escrita e colocada junto ao ramo? São tais 
"sinais" que gerem a comunicação entre os dois amantes. Os versos 51-66 explicam o objetivo da artimanha:

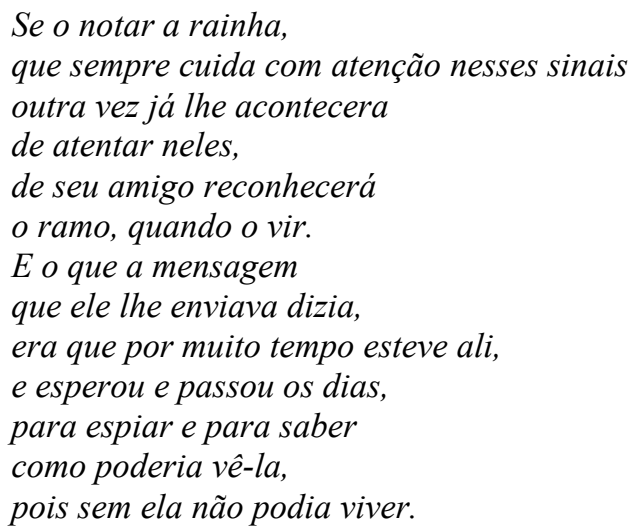

Por meio da voz de seu sujeito-enunciador ou de sua narradora, o sujeito-comunicante ou autora Marie de France busca transmitir uma história envolta em brumas, que, por sua vez, demanda o despertar dos imaginários de cada leitor/a. Temos a impressão que ela espera que esse/a leitor/a (ou sujeito-interpretante na terminologia da Semiolinguística) conclua os pontos obscuros da história com seus conhecimentos prévios sobre a história de Tristão e Isolda ou baseado em sua própria experiência amorosa. É nesse ponto que sentimos o poder dessa escrita delicada e feminina, que não esclarece tudo mas, insinua atos e gestos e é embalada por uma suave sensualidade amorosa: sabe-se que os apaixonados, sobretudo aqueles cujo amor é proibido pela lei, pela igreja e por todas as instituições que cerceiam a liberdade do ser humano são dignificados pela arte e pelos artistas em geral. Tristão e Isolda, transgressores por excelência da ordem estabelecida seriam um exemplo por excelência desse caso.

Transcrevemos, a seguir os versos 68-78 que ficaram famosos e onde, mais uma vez o sujeito-enunciador ou narrador criado por Marie de France revela/não revelando, o que é bem erótico, os sentimentos e atitudes dos dois apaixonados, aqui substituídos por uma flor (madressilva) e por uma árvore (a aveleira).

Ambos eram dois

tal qual a madressilva

que se enlaça à avelaneira:

quando estão enleadas e presas,

e todo o caule de uma envolvido pela outra,

unidas podem por longo tempo viver;

mas se há quem as queira apartar,

Gláuks: Revista de Letras e Artes - jan/jun. 2019 - Vol. 19, $N^{o} 1$ 
a avelaneira morre em pouco tempo,

e a madressilva também.

"Bela amiga, assim somos nós:

nem vós sem mim, nem eu sem vós."

Note-se aqui a inclusão de outra voz (outro "eu" ou sujeito-enunciador ) que a da narradora propriamente dita: é dada a palavra a Tristão que vai descrever a profundidade de seu amor por Isolda e vice-versa. O estratagema funciona de modo perfeito, pois Isolda (versos 81-86)

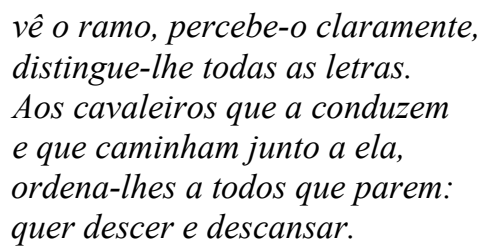

A tradução para o francês moderno do lai, feita por Berthelot (1988), nele introduz um outro "eu" ou sujeito-enunciador. A medievista coloca o verso 86 , transcrito do final do excerto acima, entre aspas e escreve: "Elle veut descendre et prendre du repos", em nossa tradução: "Ela quer descer do cavalo e descansar" (os reis e rainhas se tratavam pela $3^{\text {a }}$. pessoa, como sabemos). Desse modo o "eu-enunciador" do personagem feminino vem interromper ou se intercalar no fluxo narrativo visto como um todo. Repetimos: o lai é polifônico. E como sabemos, graças à teoria difundida por Bakhtin (1970), a polifonia confere bastante agilidade e movimento aos escritos que não se mostram fechados e permitem a entrada de outras vozes que se mesclam com a voz do narrador.

Observemos as palavras que mostram o encontro e o final do lai (versos 91-106):

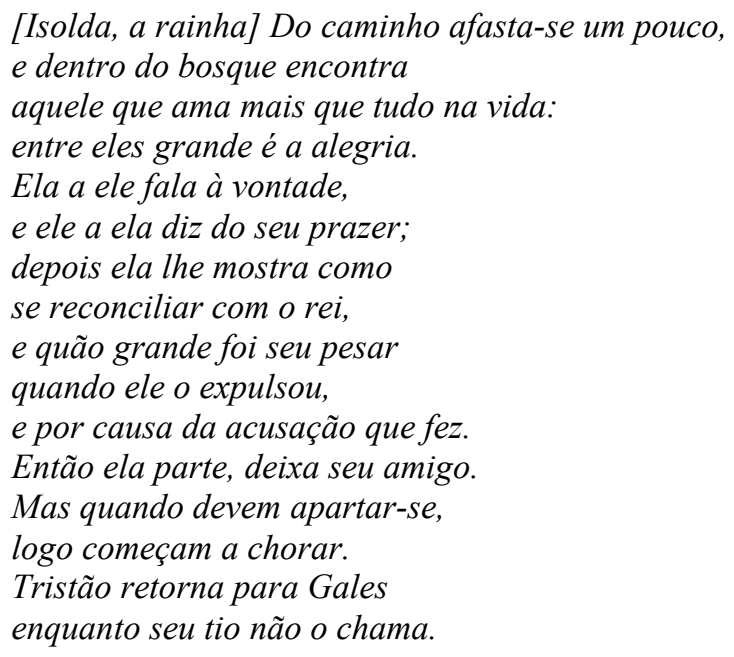


A preparação para o encontro ocupa mais o projeto de escrita da autora do lai que sua descrição propriamente dita. No entanto o verso: entre eles grande é a alegria, lembra-nos o uso de uma litotes, onde se diz menos querendo fazer entender mais. Observamos aqui um apelo ao leitor/leitora para que use sua imaginação e nela prolongue o desenrolar do encontro.

No poema em pauta, a partida é triste: os dois começam a chorar. Eles sabem que sua felicidade é uma felicidade proibida, sequestrada pelos poderes dos grandes que os governavam e mesmo pelo código da cavalaria que Tristão deveria respeitar. Como tantos amantes do mundo inteiro, são duas pobres vítimas da sociedade, das leis estritas que comandam a vida social. Ora, certamente Marie de France via frequentemente casos semelhantes na vida real.

Os últimos versos (107-118) do Lai da Madressilva mostram outro dos imaginários escriturais da época:

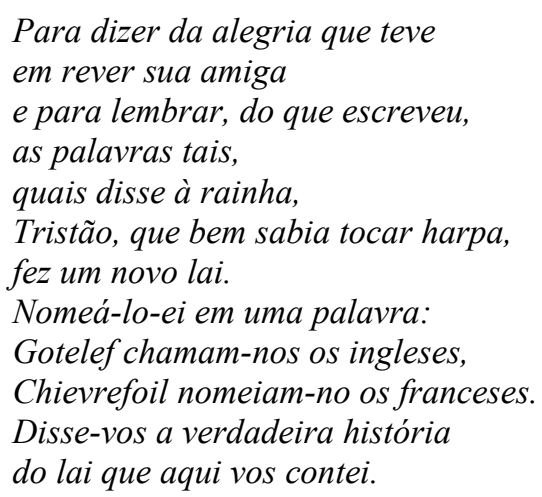

Lembramos que, em um dos comentários que seguem sua tradução, Amorim (2000) destaca um fato importante e que se acorda bem aos mistérios que envolvem Marie de France e sua história de vida, enquanto indivíduo, mulher e poetisa do século XII. Nos versos finais do lai (115 e 116) aparecem as palavras gotelef e chievrefoil. A segunda, hoje usada no francês moderno na forma de chèvrefeuille vem do latim caprifolium. Já gotelef não seria a tradução para o inglês da mesma flor (madressilva), pois, em seu lugar usa-se a palavra honeysuckle. Segundo Amorim (2000) “Gotelef é mais um mistério dos textos de Marie de France..." Mistério pleno de charme, acrescentamos.

A poetisa emprega outra estratégia narrativa: o leitor/ouvinte fica então sabendo que toda a história que leu é, na verdade, uma composição do próprio Tristão! Tal estratégia, 
ainda hoje ${ }^{9}$ utilizada, aumenta o fascínio da história. $\mathrm{E}$ os versos finais: Disse-vos a verdadeira história // do lai que aqui vos contei, chamam o leitor/ouvinte para dentro da narrativa. Ele se torna assim cúmplice de Marie de France em seu hábil jogo narrativo.

\title{
Identidades e imaginários culturais: breves reflexões
}

Tentaremos, a seguir, por meio de algumas considerações sobre o fenômeno "identidade" mostrar como ele pode ser aplicado ao poema acima transcrito.

Cabe-nos lembrar que - já há algum tempo - tal conceito é estudado por outras disciplinas que a análise do discurso propriamente dita, tais como: a sociologia, a antropologia e a psicologia social. Ora, a análise do discurso criada por Charaudeau que tem em sua base conceitos vindos dessas três áreas também assumiu tal conceito (2009, p.18-19) dividindo-o em duas partes: de um lado, teríamos as identidades sociais; de outro, as identidades discursivas. Segundo Machado,

\begin{abstract}
As identidades sociais estão sujeitas a um processo de fortalecimento, refortalecimento ou recriação e, até mesmo, a um processo de ocultação, efetivado pelo comportamento linguageiro do sujeito-falante. As identidades discursivas, por sua vez, só podem ser construídas sobre um alicerce que virá...da identidade social. Ou seja, ao propor tal divisão, Charaudeau nos mostra aqui o fenômeno identitário por meio de um movimento circular. (MACHADO, 2016, p. 112).
\end{abstract}

Como o linguista em pauta, interessamo-nos pelos sujeitos da linguagem que assumem/enunciam os discursos e com os recursos usados para captar a atenção do outro, o leitor ou o interlocutor e preocupamo-nos também com o indivíduo, com o ser humano que concebe tais narrativas. Por isso, acreditamos que estudos sobre a identidade vieram alargar o panorama analítico-discursivo charaudiano.

Mas o que seria a identidade? Como captá-la ou defini-la?

Segundo Machado (op.cit., p. 112-113) na vida prática, todo indivíduo deve ter um documento, certificado pela lei, que o identifique dos outros, contendo um determinado

9 Como o faz o romancista francês Rufin (2006) em seu livro La Salamandre. Ver também artigo de Machado (2018, p.119-132) intitulado "Le récit de vie d'une femme française dans un pseudo-paradis brésilien: La Salamandre, de J.-C. Rufin".

Gláuks: Revista de Letras e Artes - jan/jun. 2019 -Vol. 19, $N^{o} 1$ 
número, seu nome, nacionalidade, nome dos pais, uma marca biológica, uma foto...Os documentos de identidade variam de um país para outro. Eles passaram a existir

\begin{abstract}
Quando as comunidades enraizadas em territórios começaram a se tornar menos fortes, o Estado assumiu este papel. Foi assim que nasceram os papéis de identidade (Noiriel, 2007). Eles foram experimentados em populações nômades ou por operários que circulavam de uma cidade para outra: era preciso fichá-los para rastreá-los e controlá-los. (KAUFMANN, 2012, p. 13-14) $)^{10}$
\end{abstract}

Foi desse modo que o documento de identidade chegou aos dias de hoje, tornando-se uma necessidade primordial para o indivíduo que vive em sociedade. No entanto, é preciso sempre ressaltar que a identidade de uma pessoa, vista somente por meio de um documento certificado por lei, nada mais é que uma ilusão. Seria muita ingenuidade pensar que com apenas alguns dados de uma biografia simplificada é possível abranger a identidade de um ser humano: trata-se de algo muito complexo e que vai se modificando com o tempo.

Conforme o sociólogo francês Kaufmann (2012, p.14-15) a identidade se insere em um processo de construção/reconstrução, fundado na representação que o indivíduo faz de si mesmo, de sua identidade - como ser do mundo - e tenta enviar aos outros. E, ao mesmo tempo, a identidade está também nos olhares que os outros depositam sobre o indivíduo.

Refletindo sobre o esquema comunicativo proposto por Charaudeau (1983, p. 46), podemos colocar em lugar de seu sujeito-comunicativo, o indivíduo que comanda essa ou aquela interação. Para se comunicar ele não tem uma independência discursiva total: ele é habitado, influenciado, impregnado por diferentes vozes que, de algum modo, irão comandar seus pensamentos e as palavras que ele delegará ao seu sujeito-enunciador ou ao narrador/narradora de uma história.

Voltemos a Marie de France: ao escrever o Lai da Madressilva, ela delega a um sujeito de linguagem, no caso uma narradora-poetisa um fato isolado da história de dois personagens fictícios, Tristão e Isolda (o encontro no bosque). Como já foi dito, tal história faz parte do cotidiano do ser cultural que foi Marie de France, vivendo na segunda metade do século XII entre a Inglaterra e a França. Ela já leu a lenda, os comentários feitos sobre ela. No momento de transpô-la para o papel, Marie de France, enquanto indivíduo, delega a um sujeito de linguagem (o sujeito-enunciador ou o narrador) sua versão da história dos dois

10 Nossa tradução de: "Quand les communautés enracinés dans des territoires commencèrent à se faire moins prégnantes l'État a pris le relais. C'est ainsi que naquirent les papiers d'identité (Noiriel, 2007). Expérimentées sur les populations nomades ou les ouvriers circulant de ville en ville: il fallait les ficher pour les suivre à la trace et les contrôler 》. 
amantes. Ela é livre, pois, para escolher/criar/imaginar um dos muitos encontros furtivos dos amantes clandestinos, em vez de repetir ipsis litteris o que outros escritores, mais próximos de si, já escreveram sobre eles. Nesse ponto, faz uso de sua imaginação ao introduzir no poema, entre outros, o caso do ramo de avelaneira talhado em dois, no qual Tristão escreveu um nome (o seu? o de Isolda?), galho de árvore que contém uma mensagem que ela prefere que seu sujeito-enunciador (ou seu narrador) não divulgue com todas as letras: ela vai confiar no imaginário social e cultural daqueles que, como ela, já leram ou ouviram tal lenda.

Não podemos negar que o indivíduo Marie de France ao criar seus sujeitos de papel, mostra uma grande originalidade em relação aos seus predecessores e tenta manter certo mistério em sua criação (o lai em questão). Por exemplo, se o nome Isolda foi tão divulgado por outros escritores, aqui ela é só tratada de rainha. Ela casou-se com um rei e ficou mais importante socialmente. O que a torna ainda mais inacessível a Tristão.

Isso nos mostra algo ligado não só a identidade da personagem, mas também e, sobretudo, à identidade de Marie de France. Escritora vivendo em uma corte, dela recebendo proteção e lugar para escrever, ela devia respeitar as hierarquias e reconhecer o valor da posição real. Assim agindo, habilmente, ela mostra quão importante foi a mudança identitária de Isolda, que por obra e graça do casamento com Marc, sobe na hierarquia social. Ainda que ela esqueça sua realeza ao ver Tristão e se deixe levar por seus impulsos apaixonados, para o lúcido indivíduo criado do lai, ou seja, Marie de France, Isolda torna-se mais nobre e poderosa que seu amante. Tal como aconteceu, aliás, a rainha Elianor, esposa de Henrique II, no mundo real de Marie.

Marie de France, enquanto indivíduo social, pertencente a uma coletividade, deve realmente ter sido encorajada pelos seus reais protetores à pratica da arte da escrita. Mais livre que muitas mulheres da época, no entanto, ela era também prisioneira das convenções sociais que a rodeavam e que, naturalmente, respeitava.

Dentro dessa perspectiva, vê-se que Marie de France é também narradora de si mesma e, de forma sutil, retrata suas condições sociais por meio de personagens ficcionais. Mas, ela é também narradora do outro, de outras vozes que pronunciaram outras palavras, cujo eco ressoa nas suas, como diria o Mestre russo Bakthin (1970). Logo, ao imaginar a criação de um lai que contasse algo sobre os amantes da lenda celta, transmitiu ao seu ser de linguagem palavras oriundas de suas aquisições enquanto mulher culta. Assim, "por via de consequência,

\section{Gláuks: Revista de Letras e Artes - jan/jun. 2019 - Vol. 19, $N^{o} 1$}


inseriu-se em um espaço maior que o espaço sócio-histórico de sua época" (MACHADO, 2016, p. 115).

\section{Conclusão}

Chegamos ao final do artigo com uma certeza: em documentos escritos sobre vidas fictícias ou reais palpita um ser humano, enquanto indivíduo e ser social, um sujeito linguageiro ao mesmo tempo individual (em seu estilo) e coletivo (em seu tema).

O indivíduo, em sua complexidade, seja ele do século XXI ou do século XII é atravessado por constantes mudanças identitárias. O indivíduo vem do mundo, o sujeito é convocado pela linguagem. O primeiro produz o segundo.

Foi isso que buscamos ao falar sobre Marie de France e parte de sua obra: destacar certos pontos sobre a identidade da mulher-poetisa influenciada, em suas criações líricas, pelos imaginários culturais e sociais que a rodeavam e que, de uma forma ou outra, condicionaram sua maneira de escrever, chegando até ao seu sujeito-enunciador/narradora do Lai da Madressilva.

Em outras palavras, buscamos elucidar (ainda que em parte) o social e psíquico de um indivíduo que se dispôs a narrar algo e que, a nossos olhos, colocou em sua linguagem escrita "pistas" que nos conduziram (às vezes mais, às vezes menos) até ele. Social e linguagem se completam, ou como diria Gaulejac (2009, p. 12), "a sociedade é um conjunto de elementos heterogêneos, de dinâmicas que se explodem e que, no entanto, formam um sistema" considerando o "ser como um conjunto de lugares sociais que reúnem indivíduos de um mundo em comum." "No entanto, não podemos nos esquecer que

[...] há uma especificidade no interior do ser humano, um elemento irredutível que o caracteriza para além das culturas, das civilizações, das linguagens, dos contextos históricos. Algo que o anima, como ser de desejo, ativo, capaz de criações, de vontades e reflexões. [...] Podemos assim, postular a existência de um irredutível social como princípio ativo que contribui para produzir indivíduos socializados, mais ou menos adaptados à sociedade na qual vivem. (GAULEJAC, 2009, p.12-13)

11 Tradução nossa de: "La société est un ensemble d'éléments hétérogènes, de dynamiques éclatées qui pourtant font système, parce qu'ils sont au fondement de l'être ensemble des liens sociaux qui rassemblent les individus dans un monde commun."

Gláuks: Revista de Letras e Artes - jan/jun. 2019 - Vol. 19, $N^{\circ} 1$ 
Seguindo tal raciocínio, como um ser culto do mundo medieval, Marie de France se construiu de um modo especial. O que a diferencia de tantos outros está no fato de que nem todos os escritores de sua época passaram à posteridade como foi seu caso: queremos crer que ela detinha uma flama interior que a tornava única, ou pelo menos, diferente de muitos de seus contemporâneos.

Finalmente, cabe-nos explicar nossa escolha por um texto da Idade Média para ilustrar/compor esse artigo. A produção literária da Idade Média francesa leva-nos a refletir sobre a eterna luta do ser humano com as palavras, dividido entre sua criatividade e os entraves à sua liberdade.

E afinal de contas "Nossa história é escrita com lembranças. Preservá-las é fundamental para conhecer nosso passado e nos preparar para o futuro" (Martins e Neves, 2019, p. 29).

Antes de terminar, queremos agradecer ao CNPq por prestigiar nossas pesquisas sobre Análise do discurso e Narrativas de vida e ao Programa de Pós-Graduação em Estudos Linguísticos da FALE/UFMG, por nos permitir colocá-las em prática junto aos nossos alunos e orientandos.

\section{Referências Bibliográficas}

AMORIM, O. N. de. O Lai da Madressilva, de Marie de France. Tradução e Comentários. In: Revista Olhar. Ano 2, número 3, junho/2000, p. 1-8. Disponível em: www.ufscar.br-revistaolhar/pdf/olhar3/09MADRESSILVA.pdf

BERTHELET, A. Marie de France (seconde moitié du XIIe. siècle). In: BERTHELOT, A. et CORNILliAT, F. (direction) Littérature-Moyen Age et XVIe. siècle. Paris: Nathan, 1988, p.92-94.

12 Tradução nossa de: "[...] il a bien une spécificité au cour de l'être de l'homme, un élément irréductible qui le caractérise au-delà des cultures, des civilisations, des langages, des contextes historiques. Quelque chose qui l'anime, comme être de désir, actif, capable de création, de volonté ou de réflexion. [...] On peut donc postuler l'existence d'un irréductible social comme un principe actif qui contribue à produire des individus socialisés, plus ou moins adaptés à la société dans laquelle ils vivent." 
TROIES, C. de. Romans. Paris : La Pochothèque, 1994.

CHARAUDEAU, P. Langages et Discours. Paris : Hachette, 1983.

. Grammaire du Sens et de l'Expression. Paris : Hachette, 1992.

. Le discours politique. Les masques du pouvoir. Paris: Vuibert, 2005.

. Identité sociale e identité discursive. Un jeu de miroir fondateur de l'activité langagière. In: CHARAUDEAU, P. (direction) Identités sociales et discursives du sujet parlant. Paris: L'Harmattan, 2009.

GAULEJAC, V. de. Qui est « je »? Paris : Seuil, 2009.

KAUFMANN, J. - C. Quand Je est un autre. Pourquoi et comment ça change en nous. Paris: Fayard/Pluriel, 2012.

MACHADO, I.L. Reflexões sobre uma corrente de Análise do Discurso e sua aplicação em Narrativas de vida. Coimbra: Grácio Editor, 2016.

Le récit de vie d'une femme française dans un pseudo-paradis brésilien. La Salamandre de Jean-Christophe Rufin. In: ABREU, L.L.; BICALHO, A.M. (sous la direction de) Reconstructions $d u$ Brésil dans les imaginaires littéraires français et francophones. Bruxelles : Peter Lang, 2018, p. 119-132.

MARTINS, H.; NEVES, C. O lugar da memória. In: Revista Sorria, MOL Editora, jan./fev. 2019, p.29.

RUFIN, J. - C. La Salamandre. Paris: Gallimard (Folio), 2006. 


\section{Quelques réflexions sur le parcours de vie et l'identité d'une écrivaine française du Moyen Âge: étude de cas}

Résumé: L'objectif principal de cet article est de proposer quelques réflexions sur l'énigmatique écrivaine Marie de France, dont jusqu'à présent, on sait peu de chose. Sans doute a-t-elle vécu et écrit à la cour du roi Henri II, en Angleterre, dans la seconde moitié du XIIe siècle. Pour approcher un tant soit peu son histoire de vie, nous devons prendre en compte le peu d'informations biographiques que l'on trouve sur elle et contourner les lacunes par l'observation de son discours écrit. Pour ce faire, nous partirons de quelques concepts d'analyse du discours en les appliquant sur une des versions pour le portugais du poème intitulé «Le lai du Chèvrefeuille ». Nous pensons qu'en observant les pistes laissées dans cette écriture, nous toucherons - en quelque sorte - la personnalité de l'auteure. En plus d'examiner dans le récit les «Je (s)» (ou sujets-communiquant et énonciateur) qui commandent/traversent la narrative lyrique, nous aborderons l'imaginaire social et culturel qui circulait à l'époque et qui se laisse entrevoir dans le lai.

Mots-clés: sujets du discours ; parcours de vie ; récit lyrique ; identité 